\title{
Manoël Pénicaud, Le réveil des Sept Dormants. Un pèlerinage islamo-chrétien en Bretagne
}

Préface de Thierry Zarcone.

Paris, Éditions du Cerf, coll. « Alpha », 2014, 592 p.

\section{Bernard Heyberger}

\section{(2) OpenEdition}

Journals

Édition électronique

URL : http://journals.openedition.org/assr/27428

DOI : $10.4000 /$ assr.27428

ISSN : 1777-5825

Éditeur

Éditions de l'EHESS

Édition imprimée

Date de publication : 1 octobre 2015

Pagination : 346

ISBN : 978-2-7132-2515-4

ISSN : 0335-5985

Référence électronique

Bernard Heyberger, « Manoël Pénicaud, Le réveil des Sept Dormants. Un pèlerinage islamo-chrétien en Bretagne », Archives de sciences sociales des religions [En ligne], 172 I octobre-décembre, mis en ligne le 08 juin 2016, consulté le 24 septembre 2020. URL : http://journals.openedition.org/assr/27428 ; DOI : https://doi.org/10.4000/assr.27428

Ce document a été généré automatiquement le 24 septembre 2020.

() Archives de sciences sociales des religions 


\section{Manoël Pénicaud, Le réveil des Sept Dormants. Un pèlerinage islamo- chrétien en Bretagne}

Préface de Thierry Zarcone.

Paris, Éditions du Cerf, coll. « Alpha », 2014, 592 p.

Bernard Heyberger

RÉFÉRENCE

Manoël Pénicaud, Le réveil des Sept Dormants. Un pèlerinage islamo-chrétien en Bretagne, Préface de Thierry Zarcone.

Paris, Éditions du Cerf, coll. « Alpha », 2014, 592 p. 
1

Cet ouvrage est le résultat d'une longue enquête menée autour d'un pèlerinage annuel qui se déroule au hameau des Sept-Saints, commune de Vieux-Marché, dans le Trégor (Bretagne, département des Côtes-d'Armor).

2 Le lieu et l'événement, qui attirent quelques centaines de personnes, sont peu impressionnants, mais extrêmement originaux, puisqu'autour d'une chapelle $\mathrm{du} \mathrm{XVIII}^{\mathrm{e}}$ siècle construite au-dessus d'un dolmen qui lui sert de crypte, se déroule chaque année en juillet, depuis 1954, un pèlerinage où chrétiens et musulmans se retrouvent. Il s'agissait à l'origine d'un pardon breton traditionnel, mais qui a pris une autre dimension par l'action patiente et efficace de Louis Massignon (1883-1962), titulaire de la chaire de sociologie et sociographie musulmanes au Collège de France (1926-1954), qui a identifié les Sept Saints bretons avec les Sept Dormants d'Ephèse, jeunes chrétiens emmurés vivants dans une caverne pour avoir refusé de sacrifier aux dieux païens, et qui se réveillèrent de leur sommeil 198 ans plus tard. Il se trouve que cette légende est rapportée avec des variantes dans un long passage de la sourate XVIII du Coran. Les Sept Dormants (Ahl al-Kahf dans le Coran) sont donc une figure partagée entre chrétiens et musulmans et, dans les deux religions, leur histoire vient illustrer ou confirmer la croyance en la résurrection des morts. Mais ce rapprochement aurait à vrai dire échappé aux adeptes des deux confessions, n'eût été la recherche érudite et le travail de communication menés de façon volontariste, en véritable « entrepreneur », par Massignon.

Manoël Pénicaud combine l'observation sur le terrain, les entretiens avec les témoins et le travail d'archives, pour nous livrer une histoire d'un pèlerinage en train de se faire. Mais à partir d'une monographie, il brosse un tableau plus général du dialogue interreligieux et des relations chrétiens/musulmans tels qu'ils se sont développés en France depuis les années 1950.

4 L'ensemble du livre est dominé par la figure de Louis Massignon, dont l'entreprise a été poursuivie par son fils Daniel (1919-2000), qui, tous les deux ont laissé un important fonds d'archives. La trajectoire personnelle du savant orientaliste, déjà bien connue, interfère directement avec «l'invention" du pèlerinage. À côté d'une carrière académique prestigieuse, Massignon est aussi un «converti », retrouvant la foi catholique en Irak en 1906, puis un proche de Charles de Foucauld. Il combine dans son œuvre son travail d'érudition et sa quête spirituelle. C'est aussi un homme engagé dans les années 1950 aux côtés des réfugiés palestiniens, des travailleurs immigrés et de l'indépendance de l'Algérie, mais, au-delà des moyens politiques classiques, il croit à l'usage de moyens spirituels pour agir dans le monde: prière, jeûne et pèlerinage. À l'égard des musulmans, il pratique la méthode du « décentrement » : il faut sortir de soi et se substituer à l'autre pour le comprendre. Le Christ se manifeste en islam, l'Esprit

Archives de sciences sociales des religions, 172 | octobre-décembre 
Saint y «fait sourdre sa grâce ». Enfin, l'hospitalité est une vertu sacrée, qui permet d'engager le dialogue entre les civilisations. Ancré dans la foi catholique, Massignon a évolué d'une visée prosélyte envers les musulmans vers une vision eschatologique de réconciliation entre chrétiens et musulmans, suivant un mouvement perceptible alors dans l'Église, mais qui précède les avancées du Concile Vatican II en la matière.

L'œuvre du pèlerinage des Sept-Saints est emblématique de ces préoccupations à la fois érudites, politiques et spirituelles. Dès les années 1930, Massignon se livre à une enquête historique, archéologique et folklorique sur tout ce qui touche à la légende des Sept Dormants, en Europe et en Orient, et tente de retracer l'histoire de la diffusion du mythe. À Éphèse en 1951, le pèlerinage chrétien à la maison de la Vierge, qu'il visite alors, est relancé par le gouvernement turc et l'Église catholique, et attire rapidement un grand nombre de pèlerins musulmans. C'est la même année qu'il fait la connaissance du pardon des Sept-Saints, par sa fille Geneviève, et il trouve des correspondances entre le cantique du pardon breton (La Gwerz des Sept Saints) et la sourate XVIII.

6 Les premiers pèlerinages (1954-1962) se caractérisent par la faible présence des musulmans, et par des dispositions paternalistes, voire prosélytes, envers ces « NordAfricains " appartenant aux travailleurs immigrés déshérités. Malgré la volonté de Massignon de rester soumis au cadre hiérarchique de l'Église, ses initiatives aux SeptSaints rencontrent méfiance, sinon franche opposition, du côté de l'autorité ecclésiastique, qui ne veut pas se laisser déborder et déposséder. La population locale est également partagée entre surprise et hostilité, en pleine guerre d'Algérie. Malgré ces obstacles, Massignon invente des rituels qui se perpétueront après sa disparition. De 1955 à 1983, une messe de rite oriental est célébrée, d'abord en arabe, puis en grec. À une époque où l'office romain était encore en latin, le rite oriental permettait aussi de faire une place au breton et au kabyle. Une bannière consacrée à la Vierge, brodée de mots arabes, rapportée de Lourdes en 1958, ouvrira la marche de la délégation musulmane jusqu'en 1970. Enfin, la similitude entre une fontaine à sept trous, proche du sanctuaire, et une source située près de Sétif en Algérie, dédiée également au Ahl alKahf, amène à un rituel de récitation de la fâtiha et de la sourate XVIII devant cette fontaine à partir de 1961, qui reste jusqu'à nos jours le temps fort de la rencontre islamo-chrétienne.

7 À la mort du fondateur charismatique, le pèlerinage se poursuit sous la supervision de la famille, qui crée l'Association des Amis de Massignon en 1965, et grâce à l'investissement d'un certain nombre de disciples du professeur. Dans les années 1970, il est menacé d'extinction, en particulier à cause de la diminution du nombre des participants musulmans. Il connaît une seconde vie à partir de 1990. Mais il change alors d'orientation. Il est relancé par un notable local, "athée non dogmatique", appartenant à la municipalité communiste. Une association locale est fondée, dont les visées sont typiques des années 1990: utiliser le pèlerinage comme un atout de développement local, et comme un instrument du dialogue interculturel, plutôt qu'interreligieux. Mais la grande majorité des adhérents est de mouvance catholique, et non résidente à Vieux-Marché. Une autre association de riverains est fondée dans les années 2000 pour assurer l'accueil des pèlerins et le caractère festif de l'événement, avec en particulier un méchoui et un Fest Noz. Au mythe fondateur du pardon transmis par la Gwerz s'est superposé un autre mythe fondateur, autour de la personnalité de Massignon, auquel un rituel de commémoration est dédié chaque année. 
8 La fin des années 1990 voit aussi une autre grande inflexion: alors que le clergé catholique s'était montré réticent ou hostile, l'évêque de Saint-Brieuc, dont dépend la paroisse, s'investit dans le pèlerinage. À partir de 2002, le curé local occupe une place prépondérante dans l'association organisatrice et dans le déroulement des festivités. L'Église trouve alors dans la manifestation une occasion pour affirmer une identité catholique ouverte au pluralisme, mais aussi pour marquer le caractère chrétien du lieu et le retour d'une visibilité du religieux ou du spirituel dans l'espace public. Elle prône le dialogue avec l'islam, mais sans concessions doctrinales ni sans syncrétisme rituel. Cette attitude surplombante ne va pas sans soulever des objections. Elle entre en partie en contradiction avec les objectifs séculiers de développement local et de promotion du patrimoine. Elle peut rebuter les musulmans, qui, peu nombreux, restent dans la position d'hôtes invités dans un lieu et des cérémonies chrétiens. Elle est en décalage avec l'évolution des mentalités, puisque la population catholique se désaffilie du point de vue religieux, au profit d'un humanisme tolérant et universaliste, ou de nouvelles religiosités, présentes de façon discrète aux Sept-Saints. Du côté musulman au contraire, les quelques pèlerins venant au sanctuaire sont plus jeunes, et plus profondément ancrés dans leur foi, bien différents des travailleurs immigrés des années 1950 et 1960.

9 La greffe islamo-chrétienne de Massignon sur un pardon breton a transformé un événement de caractère local en événement à portée universelle. Mais les deux dimensions continuent à cohabiter difficilement dans le lieu et le temps du pèlerinage des Sept-Saints. La version intellectuelle du débat islamo-chrétien ne mobilise pas les foules, et ne répond guère aux élans spirituels du fondateur et de ses disciples. Les musulmans dorénavant résidant en Bretagne ne se sentent guère concernés par le pèlerinage. Inversement, la population autochtone non-musulmane n'est guère impliquée dans la partie islamo-chrétienne de la fête, et partage avec la moyenne de la population française les préventions, voire l'agressivité montante de la société à l'égard de l'islam.

10 Ainsi, sous la plume de Manoël Pénicaud, le pèlerinage des Sept-Saints apparaît comme un laboratoire d'expérimentation de la rencontre islamo-chrétienne, et comme un miroir où se reflètent les courants et les contradictions qui traversent la société française dans le champ du religieux. 